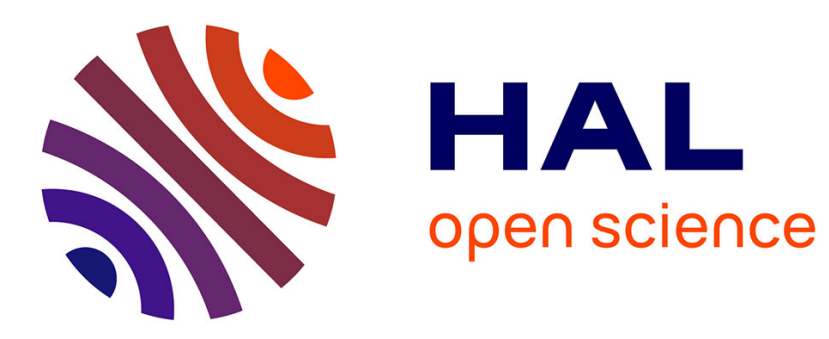

\title{
Of Pipes and Patches: Listening to augmented pipe organs
}

\author{
Christophe d'Alessandro, Markus Noisternig
}

\section{To cite this version:}

Christophe d'Alessandro, Markus Noisternig. Of Pipes and Patches: Listening to augmented pipe organs. Organised Sound, 2019, Perceptual Issues Surrounding the Electroacoustic Music Experience), 24 (Special issue 1), pp.41-53. 10.1017/S1355771819000050 . hal-02196786

\section{HAL Id: hal-02196786 \\ https://hal.science/hal-02196786}

Submitted on 29 Jul 2019

HAL is a multi-disciplinary open access archive for the deposit and dissemination of scientific research documents, whether they are published or not. The documents may come from teaching and research institutions in France or abroad, or from public or private research centers.
L'archive ouverte pluridisciplinaire $\mathbf{H A L}$, est destinée au dépôt et à la diffusion de documents scientifiques de niveau recherche, publiés ou non, émanant des établissements d'enseignement et de recherche français ou étrangers, des laboratoires publics ou privés. 


\section{Of Pipes and Patches: augmented pipe organs}

CHRISTOPHE D' ALESSANDRO* and MARKUS NOISTERNIG**

*Sorbonne Université, CNRS, Institut Jean Le Rond d'Alembert, F-75005 Paris, France

**IRCAM, CNRS, Sorbonne Université, STMS, F-75004, Paris, France

Emails: christophe.dalessandro@sorbonne-universite.fr; markus.noisternig@ircam.fr

Organised Sound 24(1): 41-53 C Cambridge University $\quad$ Press, 2019.
doi:10.1017/S1355771819000050

Pipe organs are complex timbral synthesisers in an early acousmatic setting, which have always accompanied the evolution of music and technology. The most recent development is digital augmentation: the organ sound is captured, transformed and then played back in real time. The present augmented organ project relies on three main aesthetic principles: microphony, fusion and instrumentality. Microphony means that sounds are captured inside the organ case, close to the pipes. Real-time audio effects are then applied to the internal sounds before they are played back over loudspeakers; the transformed sounds interact with the original sounds of the pipe organ. The fusion principle exploits the blending effect of the acoustic space surrounding the instrument; the room response transforms the sounds of many single sound sources into a consistent and organ-typical soundscape at the listener's position. The instrumentality principle restricts electroacoustic processing to organ sounds only, excluding non-organ sound sources or samples. This article proposes a taxonomy of musical effects. It discusses aesthetic questions concerning the perceptual fusion of acoustic and electronic sources. Both extended playing techniques and digital audio can create musical gestures that conjoin the heterogeneous sonic worlds of pipe organs and electronics. This results in a paradoxical listening experience of unity in the diversity: the music is at the same time electroacoustic and instrumental.

\section{INTRODUCTION}

\subsection{Augmented instruments and the pipe organ}

Pipe organs are complex timbral synthesisers that have always attempted to sound like singing human voices, choirs, musical instruments and orchestras of their times in an early acousmatic situation (the player often being seated in the back of the audience, hidden by pipes or the organ case). The pipe organ is a palimpsest: each era reuses the material left by the previous era, and rewrites it by covering the old with the new. After a burst of new music around the $1960 \mathrm{~s}$ that explored extended playing techniques (Walcker-Mayer 2006, 2015), the most recent addition to this development is digital augmentation: the sound is captured inside the organ case, transformed with digital audio effects and played back in real time into the acoustic space surrounding the instrument. In this way, the pipe organ can inherit the legacy of electronic and electroacoustic music while keeping its identity as a mechanical and acoustical musical instrument.

Augmented instruments have their roots in amplified electroacoustic instruments (e.g., electric guitar, electric piano, Onde Martenot, electronic organ, and Hammond organ) that appeared and were massively used in the 1930s and 1940s. Electroacoustic instruments use transducers to transform a mechanical sound source into an electrical signal. This electrical signal is then amplified and played back over loudspeakers, whereas the acoustic source is generally unperceived. The sound is thus shaped by both the amplification/playback chain and the electronic circuits, which often implement audio effects.

Following the compositional practice of musique concrète developed by Pierre Schaeffer and Karlheinz Stockhausen's masterpiece Mikrophonie I\&II, a first generation of composers used microphones to capture instrumental (and noninstrumental) sounds and transform them with analogue audio effects. However, the severe loss in audio quality and the distinct sound quality of analogue audio effects prevented a perceptual fusion between instrumental and electronic sound sources. The digital augmentation of musical instruments, at least when it aims at preserving an instrument' $\mathrm{s}$ identity, was not possible before digital signal processors (DSP) with sufficient processing power became available in the 1980s. Pierre Boulez' s Répons was one of the first music pieces combining a chamber orchestra with soloists whose sounds are digitally transformed (Boulez and Gerszo, 1988). It was produced using the 4X, a very expensive purpose-built sound-processing workstation designed at IRCAM (Lippe, 1991).

More recently, real-time digital audio signal processing became available on standard computer hardware using digital audio environments such as Max-MSP, Pure Data, Supercollider, Ableton Live, Usine Hollyhock and Kyma. Digital audio environments are integrated to digital audio workstations, offering digital audio effect libraries and easy-to-use control interfaces. These tools have been widely used for augmenting musical instruments with digital audio effects (Miranda and Wanderley, 2006; Risset, 2002; Verfaille, Guastavino and Traube, 2006), recently also including pipe 
organs.

In his doctoral dissertation, Blackburn (2011) presented a thorough discussion of four recent works for pipe organ and live electronics: (i) René Uijlenhoet' s Dialogo Sopra I due Sistemi (2003) for organ, eight microphones, laptop and four speakers; (ii) Steve Everett' $s$ Vanitas (2005) for organ and interactive electronics; (iii) Andrian Pertout' $s$ Symétrie Intégrante (2007) for flutes, organ and live electronics; and (iv) Lawrence Harvey' s Height Panels (2007/2008) for organ and a 32-channel surround speaker setup. Blackburn also reviewed improvisations for organ and electronics by Andrew Blackburn and David Corazza (Blackburn 2007, reviewed in Blackburn 2011). In 2008, the ORA project was first presented in Paris (d' Alessandro et al., 2009), soon followed by Hyun-Hwa Cho's Vox Humana for organ, video and live electronics (2009). Later, Hampus Lindwald recorded improvisations (broadcasted in French radio: Rapprochez vous du poste, France Musique, 2012) using a microphone and various software audio effects, which he controlled via a tablet computer while playing the organ. Composer and organist Franz Danksagmüller developed several innovative projects, compositions and live electronics performances with organ, clavichord, graphic tablets or new digital keyboards (Danksagmüller, 2018) using the Kyma environment (Symbolic Sound Corporation, 2018). The most ambitious organ augmentation project to date appears to be the new baroque organ in Het Orgelpark (Amsterdam). This instrument is natively equipped with MIDI, microphones and loudspeakers. A report (Fidom, 2017) describes the technical features and some on-going projects.

\subsection{Orgue et Réalité Augmentée: fusion, microphony, instrumentality}

This article discusses the Orgue et Réalité Augmentée (or 'Organ and Augmented Reality' ) (ORA) project, a musical study of digitally augmented pipe organs. The authors developed the project, which has been played in several venues since it was premiered in 2008. ${ }^{1}$ The ORA project shares several features with other DSP and organ projects: close field sound captured inside the organ case, real-time sound processing using custom-developed audio software, audio effects controlled by the performer or an additional computer musician and audio playback on integrated and/or surrounding multichannel speaker systems (d' Alessandro and Noisternig, 2012a). The audio setup described in Section 2 focuses on the installation in the church Sainte Élisabeth (Paris), which so far does not use loudspeakers surrounding the audience. The well-balanced mixture of co-located electronic and acoustic sounds allows for both fusion and sometimes strong interactions between them. Fusion and modulation result in new sound textures, including timbral and microtonal effects. New types of dynamic sounds emerge when acoustic and electronic sources combine in a feedback system. The system can also reproduce techniques known from tape music, such as delay lines, loops and time-reversed playback. Section 3 presents the outcome of different etudes and a taxonomy of combinations of pipe sets and audio effects that have been proven to work well musically; most of the sound examples were taken from d' Alessandro and Noisternig (2012b).

The ORA project's main aesthetic principles are fusion, microphony (as the auditory analogue to microscopy in optics, see Stockhausen 1971a, 1971b) and instrumentality. Fusion relates to perceptual/auditory fusion between the acoustic organ source and the added electronic/processed sounds (as opposed to electronic/ acoustic auditory stream segregation, or streaming, according to Bregman, 1990). The cognitive model of streaming is based primarily on Gestalt principles such as common fate, proximity, similarity and good continuation corresponding to acoustic grouping principles such as synchrony of onsets and spectral fusion (Bregman, 1990; McCabe and Denham, 1997). Microphony deals with the perceived aesthetic qualities of intimacy, proximity and presence. Sound is captured close to the sources, that is, close to the organ pipes, including wind and mechanical sounds. Different acoustic features of pipe ranks can be exploited to create specific electroacoustic effects, including interactive effects such as feedbacks and modulation between sound sources. Instrumentality concerns the limitation to sound material stemming from the organ (source) that feeds into the audio processing. It thus restricts electroacoustic processing to organ sounds only, without using any external source or sample playback. The musical and perceptual consequences of these principles are further reviewed and discussed in Section 4.

\section{THE ORA PROJECT}

\subsection{Pipes: Sainte Élisabeth organ}

\subsubsection{Instrument}

The organ in Sainte Élisabeth was dedicated on April 28, 1853. The instrument is a large 16-foot organ with 39 stops on three manuals and pedal (d'Alessandro, 2011). It is listed as a historical monument by the French Ministry of

\footnotetext{
1 To date, the ORA project has been installed for concerts or workshops on different pipe organs: Sainte Élisabeth, Paris; Saint Michel, Lille; concert hall organ, Bouzy; Palais des Beaux-Arts (BOZAR), Brussels. Concerts took place in Paris in 2008 (funded by the Science sur Seine project of the city of Paris) and in Lille in 2010 (opening concert of the European Heritage Days, funded by the city of Lille). An audio CD was produced in 2012 (Hortus Edition), followed by concerts in Paris in 2015 (organ concert series, Sainte Élisabeth) and a workshop in Bouzy in 2016.
} 
Culture, and it has been restored in its original state ${ }^{2}$. This means that the instrument can be played without any electric power. Mechanical linkages only are used for the registers, keyboard coupling, swellbox control and tracker action (keys and pedals). An electric blower is available for filling the four large wind reservoirs. However, the original manually operated bellows can fulfil 1 the same function. Hand-pumped wind allow for extended techniques and control of all the details of sound production. Table 1 and Figure 1 show the disposition and a picture of the organ, respectively. The organ case is organised according to the Werkprinzip, that is, each division of the instrument is located in a separate organ case enclosing the corresponding pipes. The dimension of the organ is about 10 by 10 metres, with three main levels for the four divisions (see Figure 1) and a total of 2,322 pipes, of which 141 are visible façade pipes. The positif (420 pipes, 8 stops) is an $8^{\prime}$ case on the floor of the organ loft and corresponds to the fi rst manual keyboard. The grand orgue (1014 pipes, 13 stops) and pédale (180 pipes, 6 stops) at the main level correspond to the second manual keyboard and pedal board, respectively. The récit ( 708 pipes, 12 stops) case is about the same size as the positif and crowns the instrument; it is enclosed in a swell box and corresponds to the third manual keyboard.

Table 1: Stop list, Sainte Élisabeth

\begin{tabular}{|c|c|c|c|}
\hline Positif & $\begin{array}{l}\text { Grand } \\
\text { Orgue }\end{array}$ & Récit & Pédale \\
\hline Basse de flûte $8^{\prime}$ & Flûte $16^{\prime}$ & $\begin{array}{l}\text { Flûte } \\
\text { allemande } 8^{\prime}\end{array}$ & Bombarde 16' \\
\hline Dessus de flûte $8^{\prime}$ & Montre $8^{\prime}$ & Bourdon 8' & Trompette $8^{\prime}$ \\
\hline Bourdon 8' & Bourdon 8" & Gambe 8' & Clairon 4' \\
\hline Prestant 4' & Flûte $8^{\prime}$ & Voix céleste & Soubasse 16' \\
\hline Kéraulophone $8^{\prime}$ & Prestant $4^{\prime}$ & $\begin{array}{l}\text { Flûte } \\
\text { octaviante } 4^{\prime}\end{array}$ & Flûte $8^{\prime}$ \\
\hline Nasard 2'2/3 & Gambe 8', & Cornet $V$ & Flûte $4^{\prime}$ \\
\hline Basson 8' & Octavin 2' & Gambe 4' & \\
\hline Hautbois 8' & Plein jeu $V$ & Cor anglais 16' & \\
\hline Trompette $8^{\prime}$ & $\begin{array}{l}\text { Grand } \\
\text { cornet } V\end{array}$ & Trompette $8^{\prime}$ & \\
\hline Basse clairon 4' & $\begin{array}{l}\text { Bombarde } \\
16^{\prime}\end{array}$ & Hautbois $8^{\prime}$ & \\
\hline \multirow[t]{2}{*}{ Dessus clairon 4' } & $1^{\circ}$ Trompette & Clarinette 8 ' & \\
\hline & $\begin{array}{l}2^{\circ} \text { Trompette } \\
8^{\prime} \\
\text { Clairon } 4^{\prime}\end{array}$ & $\begin{array}{l}\text { Voix humaine } \\
8,\end{array}$ & \\
\hline
\end{tabular}

With 12 combination pedals:

Appel/retrait flûte 16' G.O. Appel/retrait bombarde G.O. Tirasse III Tirasse II
Tirasse I

Coupling III/II

Coupling I/II

Expression Récit
Anches G.O.

Anches Récit

Anches Pédale

Trémolo Récit

\subsubsection{Pipe sounds}

A pipe organ produces sound with hundreds or thousands of pipes, each of which produces a single pitch and timbre (see Pollard 1999, and Angster, Rucz and Miklós 2017, for an introduction to pipe-organ acoustics).

Reed pipes are characterised by a rich spectrum and a relatively loud tone, and the bass and treble registers are somehow unbalanced in their loudness profile; the bass is typically much louder than the treble. The attacks and transients are very short and not very prominent. Strong reeds saturate the spectrum and are therefore often used for creating powerful, strong acoustic effects in traditional organ music. A reed pipe is characterised by a broadband harmonic excitation source (the reed itself) filtered by a resonator (the organ pipe). In terms of sound production, reeds

\footnotetext{
2 Christophe d'Alessandro is organiste titulaire of Sainte Élisabeth in Paris. As a member of the French Commission Nationale du Patrimoine et de l'Architecture, he participated in the supervision of the restoration project in 1999.
} 
can be represented by a source-filter approach. Some ranks, such as the voix humaine, exploit this source-filter feature: they are built with short pipes yielding spectral resonances similar to the vocal formants of the human voice, close to the vowel /a/.

In contrast to reed pipes, the spectrum of flue-pipe sounds is limited to a few harmonics. The transient sound is sometimes clearly audible and allows for a large variety in articulation. Flue-pipe ranks fuse well because their spectrum exhibits only a few harmonics. Organ registration is historically the first form of acoustic additive synthesis. Flue pipes in octave relationships are commonly combined (foundation stops) for varying the sound power and brightness, with a homogeneous timbre. The mutation registers are combinations of several pipes with harmonic relationships that create a specific timbre. Flute ranks are combined in mutation registers such as the cornet or jeu de tierce (usually, the fundamental, octave, fifth above the octave, double octave and third above the double octave). Acoustic fusion of artificial harmonics allows for synthesis of a new timbre.

Mixture stops, such as the plein-jeu, fourniture, cymbale or mixtur or scharf, are special combinations of harmonically related flue pipes. These stops are always used in addition to foundation stops. Several ranks of octaves and fi fth (sometimes also a rank of third: cymbale-tierce) are played together. But unlike the mutation stops, there are breaks in the progression, so when the rank pitches reach a given ceiling, they break back to lower pitches. This ceiling effect, adding volume and brilliance to the sound, results in the organo pleno typical sound. It is somehow comparable to a saturation effect: whatever the note played, the acoustic spectrumis fi lled with high harmonics. This is not only additive synthesis, but also additive synthesis with a kind of controlled spectral aliasing because of the breaks.
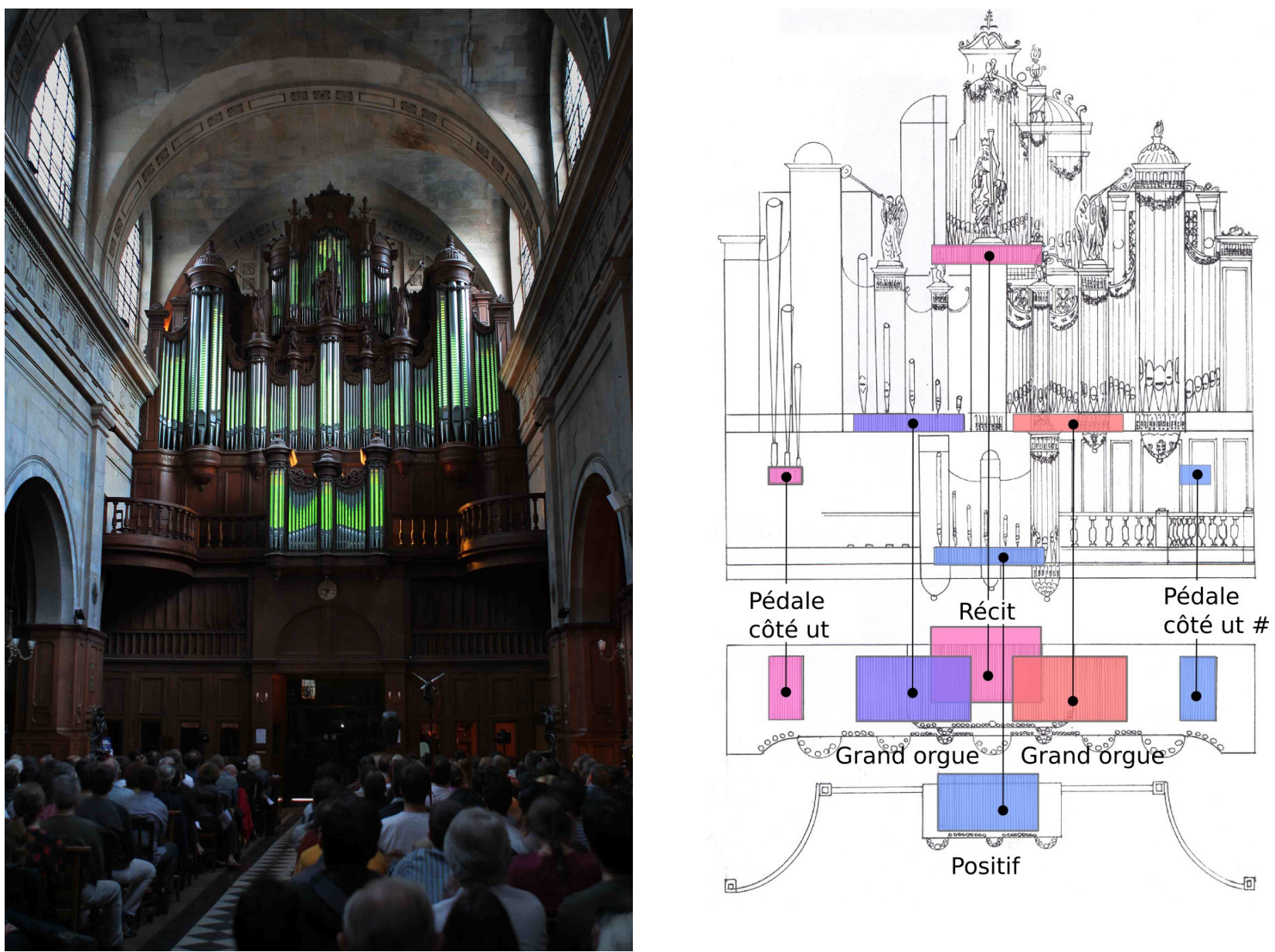

Figure 1. ORA concert in Paris (2008). In this concert, the instrument's façade is animated by the played music as described in Jacquemin, Ajaj, Le Beux, d'Alessandro, Noisternig, Katz, and Planes (2010). In the right panel, implantations of the microphones in the organ division are displayed.

\subsubsection{Accessories and other sound sources in the organ}

In the romantic organ, slightly detuned ranks of identical pipes are often associated. Detuning between pipes produces acoustic beats and then an undulating effect. The slightly sharp tuned rank is often called the voix celeste (French organ), strings (American organ) or voce humana (Italian organ).

Since the eighteenth century, one or more divisions of the instrument can be enclosed in a special case: the swell box. This case is enclosed with shutters that are driven by a pedal at the organ console. When shutters are closed, the sound is softer and seems distant. In contrast, opening the box gives a crescendo effect, mainly by a sound reinforcement for 
higher harmonics.

Tremolo or tremblant are placed in the wind channels before the chests. These devices induce fl uctuations of the wind pressure, usually with a moving piece of wood oscillating in a channel (tremblant doux), or by a small oscillating gate in a channel (tremblant fort).

Keyboard actions and registers result in mechanical noise, the blower and the air $\mathrm{fl}$ ow in wind noise. Mechanical and wind noises are typically unwanted and should be kept to a minimum, almost inaudible at the listener's position for a well-built instrument. The organ player can make additional sounds, such as percussive finger tapping. To make these noisy and airy sounds available for audio effect processing, additional reference microphones have to be positioned close to the sound-emitting regions. All these sources of sound can be processed, amplified and mixed in the outer acoustic space. The wind noise, for example, has a rich spectral content, and fl uctuations can be obtained by manual control of the keyboard or the blower.

\subsection{Patches: custom software developments}

An interdisciplinary approach to digital audio effects classification (Verfaille et al. 2006) identifi es about 70 items. A subset of the available audio effects has been chosen for this project. The question was to explore the perceptive features and musical material obtained by interaction of organ sounds and audio effects rather than to make a systematic investigation of all possible effects. The main families of effect described in Verfaille et al. (2006) on the basis of implementation techniques are represented in our project: spectral and time domain effects, including filters, delays, modulators, non-linear feedback processing, time-segment processing, time-source-filter processing, spectral processing and time and frequency warping. These audio effects modify the perceptual attributes of pitch (height and chroma); melody, intonation, contour, harmony and harmonicity; glissando; dynamics (nuances, articulation, legato, accents and tremolo); time (duration, tempo and rhythm); and timbre (formants, spectral colour, brightness or spectral height, quality, texture and harmonicity; vibrato). Spatial effects are limited to reverberation and echoes because we wanted to preserve colocation of acoustic and electronic sources.

The ORA software is a framework for digital audio effects for augmented pipe organ ${ }^{3}$. All effects are programmed in the visual programming language Pure Data (Puckette 1996, 2007). The framework provides a modular architecture that is easy to extend and adapt to different instruments. In its current version, the software provides artificial reverberation based on feedback delay networks with mirror-source modelling for early reflections; feedback delay lines with controllable feedback gains and delays; multichannel harmonisers that provide transposition (in cents) for each channel; and a Karplus-Strong string resonator with spectral stretching. All effects can be routed to a reverberation bus, for which the send gain controls the direct-sound-to-reverberation ratio. Each effect unit has a programmable input matrix for routing the microphone signals to the different audio effects. The software also provides a powerful cue engine to trigger events and combine different effects. All effect parameters can be controlled over MIDI and/or Open Sound Control (OSC). The concerts and musical studies used MIDI motor-fader boxes and graphic tablets that provide fast and accurate control of effect parameters and sound levels.

\subsubsection{Delay lines}

Programmable delay lines with multiple outlets simply delay the microphone signals before they are played back over loudspeakers. The two control parameters are the delay time (in $\mathrm{ms}$ ) and the attenuation factor (in $\mathrm{dB}$ ). Time delays are additive audio effects, because electronic and instrumental sounds superimpose additively. Depending on the delay times, attenuation factors and number of delay channels, a large variety of temporal and timbral effects can be produced. An additional feedback delay mode uses ring buffers instead of time-varying delay lines to create dense and richly coloured sound layers. The time delay can provoke audio feedback, which can be used for interactive audio effects. Note that the simple delay lines differ from the comb filter effect discussed in 2.2 .3 because the latter provides an infinite loop and a low pass filter.

\subsubsection{Harmonisers}

Programmable harmonisers use delay line modulations (Zölzer 2002) for shifting the whole signal spectrum by a given shift factor. The two control parameters for each harmoniser are frequency shift (in cents) and attenuation (in $\mathrm{dB}$ ). In practice, the microphones capture the global sound of each organ division rather than the sound of individual pipes. Applying a harmoniser to this polyphonic mixture produces large number of inharmonic partials that add to the original signal spectrum. This creates a very dense and inharmonic sound. Various shifting ratios are used to produce different degrees of inharmonicity and different types of effects.

\subsubsection{Spectral stretching and comb filtering}

Subtractive synthesis is used to spectrally shape sounds with an overtone rich spectrum. The Karplus-Strong algorithm (Karplus and Strong 1983) provides a computationally efficient and simple approach to subtractive sound synthesis. It simulates the travelling waves of a vibrating string using a delay line and a low pass filter in a closed loop. This creates a comb filter effect for which the fundamental frequency is defined by the length of the string; low and medium

\footnotetext{
3 Markus Noisternig designed and developed the live-electronic effects in this project. The effects are partly inspired by works with Thomas Musil (Institute of Electronic Music and Acoustics, University of Music and Performing Arts, Graz) and by numerous projects with Klangforum Wien, Ensemble Intercontemporain and Ensemble Modern.
} 
resonance frequencies are controlled by the delay time (Zölzer 2002). The Karplus-Strong effect is applied to the microphone signals, which can be pre-processed with a frequency stretcher. The latter combines a frequency shifter (frequency modulation) with a harmoniser (frequency transposition) to increase/ decrease the signal's spectral density. The Karplus-Strong effect provides the control parameters: string resonance (in $\mathrm{Hz}$ ), attenuation factor (in $\mathrm{dB}$ ) and stretch factor. Using time-varying delays, which can be controlled in real time, creates resonance motions very similar to formant motions in the human voice spectra.

\subsection{Installation}

\subsubsection{Inner sound capture}

The principles for augmentation of the pipe organ are somewhat different from those used for other instruments because of its large size. The pipe organ is made of thousands of spatially distributed sound sources, the pipes. Each of these sources has its own pitch, intensity, timbre and sound radiation pattern, depending on its type (flue pipe, reed pipe or open or closed pipe). The size of the pipes varies greatly, with vibrating lengths ranging from less than a centimetre up to several metres and diameters from a few millimetres to tens of centimetres. Most of the pipes are enclosed in cases, with the notable exception of the visible pipes in the organ façade. The case has two main functions: on the one hand, pipe sounds inside the case are mixed, including multiple reflections on the interior walls, on the other hand, cases are generally open on only one side, directing the sound radiation to the outer space. The façade appears as a screen radiating sound in the frontal direction and provides sound insulation towards other directions. In Sainte Élisabeth, the four divisions are clearly apparent on the organ façade and correspond to four spatially distributed and somehow separated parts of the organ case. Figure 1 shows the organ façade and the internal organization of the instrument.

For digital augmentation, sound is better captured inside the different divisions of the instrument. Ideally, the different divisions should be acoustically well insulated (at least for mid and high frequencies), allowing for separate processing of the different divisions. In Sainte Élisabeth, the positif de dos is enclosed in a separate case situated at the edge of the organ loft. It is more than a metre away from the main case and radiates towards the front. The inner sound is therefore strongly attenuated towards the other directions. The récit expressif is enclosed in a swell box, which provides a controlled attenuation of the radiated sound. This division is well insulated except in the frontal direction and is controlled by a swell pedal. Grand orgue and pédale divisions are at the same level on the same floor. They are diatonically disposed, with a $\mathrm{C}$ and a $\mathrm{C} \#$ side. These two divisions are not acoustically separated. Therefore, the four organ divisions correspond to only three acoustic divisions, that is, three parts of the instrument that are sufficiently acoustically insulated.

The sound quality strongly depends on the type, number and positions of the installed microphones. Omnidirectional microphones (pressure microphones) have lower distortions and a lower limiting frequency compared to directional microphones. To avoid distortions due to the high sound pressure levels close to the organ pipes, microphones with a high dynamic range have been used (DPA 4061 miniature omnidirectional pre-polarised condenser microphones). The captured sound is not homogeneous and not well equalised for all the pipes due to the large variety in pipe dimensions and the different distances from the microphones. Note that some of the pipes are placed on the façade and are therefore not well captured by the interior microphones. Fortunately, this is limited to a relatively small number of large pipes, corresponding to parts of one or two ranks for each division. Perceptually, the sound captured inside the case differs significantly from the sound perceived outside the case. The inner sound is almost not influenced by the room reverberation, and it is much more intense, in particular at low frequencies. Its transients are very sharp and more precise than in the sound outside the organ. Capturing the inner sounds offers the acoustic equivalent of the magnifying lens approach: subtle sounds that are generally not audible are amplified and transformed, and wind and action sounds and sounds of small individual pipes can be amplified and processed.

\subsubsection{Co-located sound diffusion}

The inner sounds are produced by the pipes and mainly radiate through the organ's façades in frontal directions. The façades are quite large and distributed in space, which results in a large apparent source width (Katz and d'Alessandro, 2004). The multiple acoustic sources are blended in the reverberant outer space, giving birth to the global organ sound. The huge dimensions of typical pipe organs naturally inspired several spatial effects in classical organ music:

- Divisions with different dynamics are used for antiphonal or echo effects;

- The swell box gives an impression of closeness or remoteness of the enclosed pipes by opening or closing venetian blinds;

- Different keyboards with similar registrations are often used in dialogues, polyphony, solo or similar rhetorical effects.

The electroacoustic sounds can be diffused in different locations, depending on aesthetic choices ${ }^{4}$. In most concerts and for recordings, co-located sound diffusion is preferred. For co-located sound diffusion, two wideband loudspeakers and subwoofers are integrated into the organ case so that they are not visible to the audience during the concerts. Note that

$4{ }_{4}$ Different solutions have been used for sound diffusion in the different versions of the ORA projects. A setting with spatial sound diffusion is described in d'Alessandro et al. (2009). 
the electronic sound must be adjusted (or voiced, according to organ building terminology) to match with the acoustic sound and the room. Therefore, room-acoustic measurements are conducted for each venue and system, and a multiband equaliser is used to compensate for the room-specific resonance effects.

Acoustic and electroacoustic sounds are balanced. The power of the sound system is carefully adjusted to match the pipes' sound level to achieve a near perfect fusion of both types of sounds. Although colocation of both sound sources increases perceptual fusion because all sound sources are coming from the same location, it also favours audio feedback, which limits the overall dynamics of the sound system. This could be alleviated by treating the cabinets/cases acoustically to achieve greater acoustic isolation between loudspeakers and microphones. However, structural alterations to the pipe organ are often not possible in practice.

\subsubsection{The role of the performers}

In the ORA project, usually two performers ${ }^{5}$ play together: an organ player and a computer musician. The organist plays the keyboards and pedal board, selects the stops and controls the couplers, the swell box and other accessories. The computer musician controls various interfaces, such as mixing desks, MIDI interfaces, foot pedals, graphic tablets and the computer keyboard.

Obviously, the organist is busy with her/his task, and any other demand would be somehow detrimental to virtuosity. Playing in duet with another musician is a source of musical enrichment because the computer musician can develop his/her own kind of virtuosity in manipulation of effect controllers. This is in line with a remark by Blackburn (2011: $183)$ :

Increasingly in this new repertoire, the organist is no longer a solo player; registration assistants now take responsibility for shaping the sound during the performance and, given the late twentieth century aesthetic of timbral exploration, their artistry and taste are important to the success of the performance. These changes all occurred before the arrival of real-time electronic manipulation of the sound. 'Co-performers' with the organist - registrants have a role creating the sounds (e.g. in Vanitas and Harmonies) - now meaning the organist is becoming conductor and collaborator with others in the performance. Action noises and half drawn stops are now included within the canon of the pipe organ's timbral repertoire.

Figure 2 summarises the three points discussed in this section. The bottom panel represents the organist's action (the musical score), the middle panel displays the spectrogram of the inner sound, captured by the microphones (Sound Example 1) and the top panel the spectrogram of the outer sound perceived by the audience (Sound Example 2).

\section{MAKING MUSIC WITH THE AUGMENTED ORGAN}

Creating a new sound, a new musical object or a new musical structure with the augmented organ involves three components: a source of sound, a processing algorithm and controls of both the instrument and the algorithms. Effects can conveniently be analysed along two lines.

- $\quad$ Paradigmatic and syntagmatic effects. Paradigmatic effects are synchronous modulations or transformations of the source. Syntagmatic effects involve some transformations or modulations of the sound source over time. Paradigmatic effects with fixed parameters are timbre effects, equivalent to registration, instrumentation or orchestration for instrumental music. When paradigmatic effects are dynamically controlled, the musical texture can give birth to timbral polyphony, that is, perceptual segregation into timbral auditory streams. In syntagmatic effects, some material is delayed, replayed reversed or repeated. The acoustic source and processed sounds are no longer synchronous. This corresponds to contrapuntal or polyphonic texture effects, loops and inversion in time.

- $\quad$ Interactive and non-interactive effects. Some effects are non-interactive because the resulting sound is only the addition of acoustic and electronic sources. The electronic source depends on the acoustic source, but the acoustic source is not modified by the electronic source. For interactive effects, modulations between acoustic and electronic sources result in dynamic sounds that are not the mere addition of both separate sources. A classical interactive effect is the Larsen effect, but other types of interactive effects are also possible in the specific context of the augmented organ.

Depending on the effect types, the sound sources and the control of both, very different behaviours and musical possibilities are offered by the augmented organ.

\subsection{Extended registrations}

Applying paradigmatic effects to pipes results in extended registrations. The pipes sound with a different tonal quality or timbre because they are mixed with electronic sounds; however, they respond like ordinary pipe ranks.

\footnotetext{
5 A third musician was also involved in some projects for pumping the air. This has the advantage of eliminating the electric blower noise and also adds some expression to the wind itself.
} 

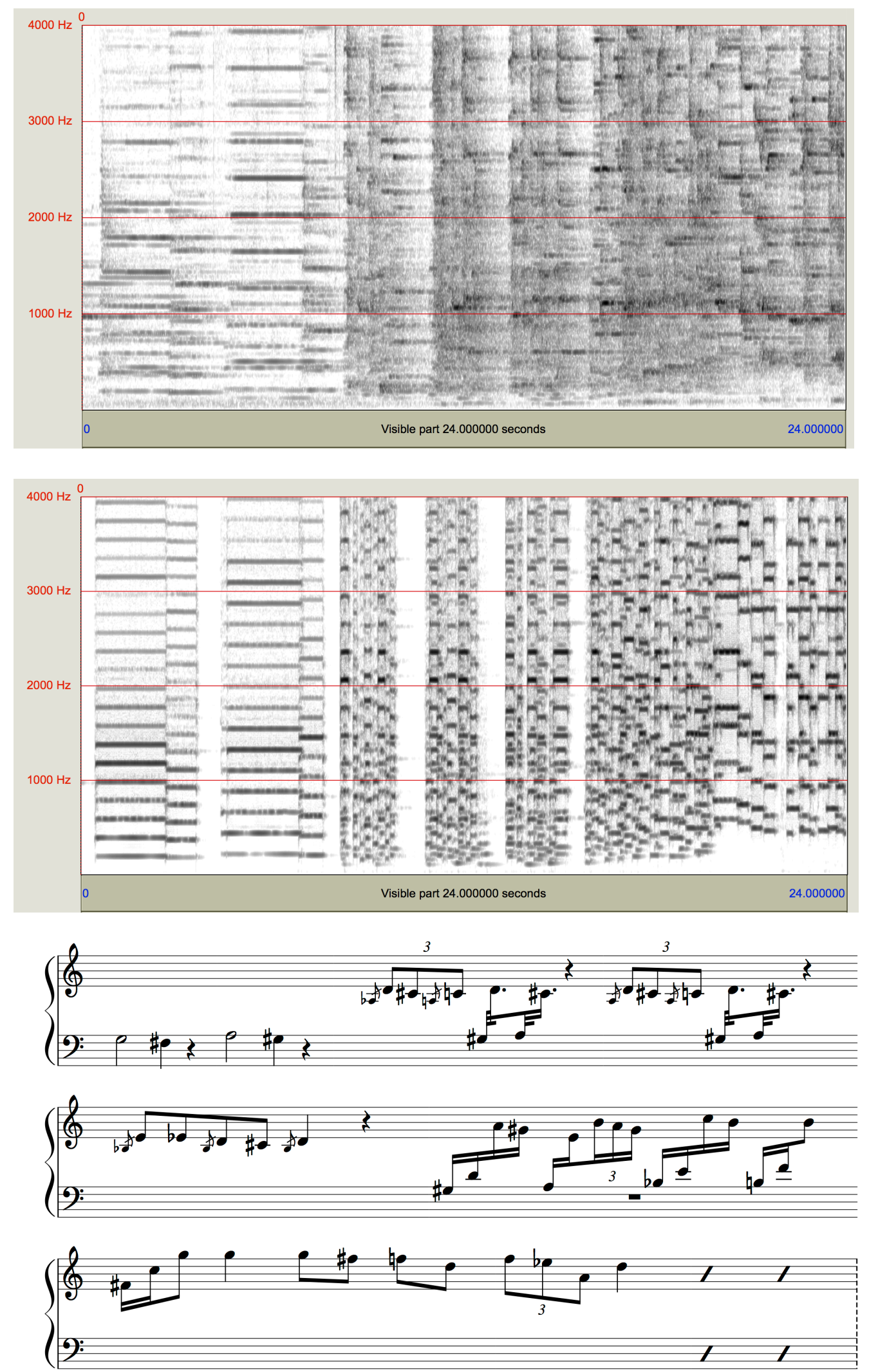

Figure 2. Effect of the Karplus-Strong algorithm: spectrogram of the outer sound at audience position, with visible formant motion (Sound Example 2). Middle: spectrogram of the inner sound in the Récit division (Sound Example 1). Bottom: corresponding score (played on reeds). 


\subsubsection{Inharmonic mixtures}

Inharmonic mixtures are obtained by processing flue pipes with the harmoniser. Artificial high frequency partials are obtained by addition of the frequency shifted input signal. The global sound is captured by the microphone: not only fundamental frequencies, but also all the partials of all notes of the sound are transposed and mixed, resulting in an inharmonic global effect. The effect is particularly effective for pipes with a relatively poor spectral content, such as flue pipes. The resulting sound gains in brilliance. Examples of interesting frequency shifts are between an octave and two octaves (1,200-2,400 cents). Played in the high registers for small pipes (e.g., 4' ranks), the timbre is close to small bells. In the medium low register, the sound has a metallic quality, somewhat similar to bowed metal plates (Sound Example 3).

\subsubsection{Inharmonic distortion}

Applying harmonisers to reeds or mixtures with already spectrally rich sounds saturates the spectrum. These saturation effects sound somehow like inharmonic distortion or overdrive effects for amplified instruments because of the many inharmonic partials that are added to the acoustic spectrum. Loudness is much higher than for inharmonic mixtures (Sound Example 4). 3.1.3. Harmonic mixture and chorusing A chorusing effect is obtained when the harmonisers are used with harmonic pitch shifts. For instance, major or minor thirds give a major or minor choral quality to the sound. Depending on the desired musical content, consonant harmonic intervals such as pure fifth, pure fourth, major or minor thirds, major or minor sixths and dissonant intervals such as augmented fourth or seconds can be used.

\subsubsection{Spectral composition}

Composing the sound spectrum by combining partial sounds is reminiscent of the musique spectrale. The sound spectrum can be composed using artificial partials derived from the harmonisers and added to the acoustic sound. This can be achieved with accuracy by using the harmoniser gains and frequency shifts.

\subsubsection{Timbral tiling}

Delaying the signal with short delays (e.g., $20,40,60$ or $80 \mathrm{~ms}$ ) and adding the output to the original sound produces soft, progressive attacks. This effect is called 'tiling' because delayed sounds do overlap, in analogy to how clay tiles overlap over each other. For the tiling effect, delays should be in the length of consonantal transients, that is, between $20 \mathrm{~ms}$ and $40 \mathrm{~ms}$. Then the acoustic sound is reinforced by the delayed sound; this changes the sustained part of the sound, adding a slightly chorused quality. The build-up and decay of the acoustic sound and additional delayed sounds shape the attack and release transients. This timbre effect is particularly effective when varying expressive articulation. The release and articulation are less precise, with some kind of reverberant quality. This effect is better used in conjunction with soft registrations made of flue pipes or soft reeds (Sound Example 5).

\subsubsection{Stacked sounds}

Multiple delays with shifts of less than one second (e.g. 200, 400, 600 or $800 \mathrm{~ms}$ ) result in a multi-layered or stacked sound. This gives dynamics to the notes, with some amplitude building and timbre thickening; the acoustic sound is slowly reinforced by the delayed sounds. The attack and release transients are slow. This effect gives a lively, dynamic and chorused quality to the sound. Again, this effect is particularly effective with soft registrations made of flue pipes or soft reeds (Sound Example 6).

\subsubsection{Microtonal stops}

Microtonal solo stops are obtained when closing the swell box for attenuating the acoustic sound as much as possible. The electronic sound can be shifted by a fraction of a semitone and played back louder than the acoustic sound. This, for instance, allows for playing quartertone flutes using two keyboards at a quartertone distance (Sound Example 7).

\subsubsection{Microphony}

Microphony explores the subtle sounds that are usually unheard in organ playing. Electronic amplification and processing change the natural balance between wind, action and pipe sounds. A soft flute stop can sound louder than a choir of reed stops. Because the action noise is clearly audible in a tracker action organ, this sound can be amplified and processed. Percussive plays on the organ case can also be processed by microphony. The organ in Sainte Élisabeth can be played with a hand-operated pump. This allows for an expressive control of the wind supply and wind variations; wind sound is a continuous, slowly varying broadband noise and adds expressive wind play to the audio effects (Sound Example 8).

\subsection{Syntagmatic effects}

\subsubsection{Contrapuntal figures and echoes}

Playing back sequences with a delay of several seconds, possibly with several delay lines, gives birth to contrapuntal figures of imitation or echo. In this case, the electronic sounds must sound as similar as possible to the acoustic sounds. This is obtained by careful adjustment of the sound level and timbre quality (Sound Examples 9, 10 and 11 


\subsubsection{Shadows}

Delay times of 500-1000 ms results in sound shadowing effects that are close to echo effects. Additional timbre modifications amplify this effect. The played melody is followed by its repetition, like a shadow follows a moving object. Strictly speaking, it is not a counterpoint figure, but rather a coloration of the melody (Sound Example 12).

\subsubsection{Tape music effects}

Sound captured on the fly by the microphone can be processed with all kinds of effects derived from tape music, such as time reversal, superposition, loops and delays (Sound Example 13, time reversal).

\subsubsection{Gliding registrations}

Gliding registrations are obtained by a continuous variation of parameters, such as frequency shifts, the Karplus-Strong resonance frequency or the frequency stretching. Gliding tones and complex gliding spectra are completely outside the vocabulary of traditional organ music (Sound Example 14).

\subsection{Interaction and feedback}

Interactive and feedback effects are possible when the acoustic and electronic sources are co-located (i.e., close to each other). A typology of feedback effects can be found in Sanfilippo and Valle (2013).

\subsubsection{Beats and undulant registrations}

When one uses a harmoniser with a very small frequency shift (e.g., 20 cents), the electronic and acoustic sound spectra interfere and give birth to beats. This undulant sound effect is similar to the voix céleste stop of the romantic organ, but unlike the voix céleste, it can be obtained with any registration. Beating frequencies can be accurately adjusted and varied. The resulting pitch is slightly detuned, that is, an average between the acoustic and electronic pitches (Sound Example 15).

\subsubsection{Harmonic glides}

Harmonic glides occur when one uses two slightly detuned harmonisers (e.g., using frequency shifts of 20 and 30 cents) in a feedback loop. A sound that is slightly frequency shifted by the harmoniser is captured by the microphone and then shifted again. This yields an ever rising sound. For this effect, the playback level must be high enough to make sure that the feedback gain is slightly larger than one (Sound Example 16).

\subsubsection{Chaotic transients}

Reed pipe sounds have a rich frequency spectrum that can be shaped by subtractive synthesis techniques such as filtering. The Karplus-Strong effect associated to spectral stretching and feedback gives complex spectral modulations because several oscillators are coupled through the feedback loop: the Karplus-Strong resonance frequency, the acoustic fundamental frequency and the frequency shifted and stretched electronic sound. Transients show chaotic spectral motions. The results are reproducible when all the parameters are fixed, but they are highly unpredictable, with considerable variation for different notes played on the keyboard or different parameter settings (Sound Example 17).

\subsubsection{Formant filtering}

The resonance frequency of the Karplus-Strong algorithm can shape the spectrum of rich sound mixtures, such as reeds or plenum registrations. Below $200 \mathrm{~Hz}$, this resonant frequency is in the range of speech prosody. In the $200-800 \mathrm{~Hz}$ range, this resonance is close to the first vocal formant, associated to jaw opening in speech. Frequency variations sound such as $/ \mathrm{a} /$-to-/ $\mathrm{u} /$ or $/ \mathrm{a} /$-to-/i/vowel transitions (Sound Example 18). In the 800-3000 Hz range, this resonance is close to the second vocal formant, associated with front back articulation in speech. Frequency variations sound such as /i/-to-/u/ vowels transitions. Above $3000 \mathrm{~Hz}$, this resonance has no more vocalic quality, but it brings some spectral enrichment, similar to increased vocal effort in speech. Spectral formant motions sound like emerging gliding vowels, making the pipe organ sound like a giant human voice. The note stream (on the keyboard) and the vowel/formant stream (resulting from dynamic spectral shaping) play in polyphony (Sound Example 19).

\subsubsection{Larsen effect}

The Larsen effect (feedback and ringing) is often undesirable, but sometimes it is useful in a musical sense. It appears when the overall gain in the feedback loop is close to or larger than one. To avoid unpredictable behaviour, this effect requires accurate control of playback level and microphone gains. 


\section{THE PHENOMENOLOGY OF LISTENING TO AND PLAYING THE AUGMENTED ORGAN}

\subsection{An acousmatic situation?}

Bayle (1993: 18-19, 179-80) retraces the origin of the word 'acousmatique' in the context of electroacoustic music. This term has at least two meanings. The original meaning is associated with the Pythagorean

school (Kane 2014: 45-72). It refers to the experience of listening to a known source (Pythagoras himself) hidden by a veil (listening without being disturbed or influenced by the vision of the speaker, origin of the sound and speech). However, the source is well identified and recognised. In many cases, the audience's experience of organ concerts is, strictly speaking, an acousmatic situation according to this meaning. The performer is often hidden by the organ case, and the audience, at least in many ancient churches, is seated with their backs to the instrument. This natural acousmatic situation, together with unusually large and reverberant acoustics, is part of the magic of organ music. Blackburn (2011: 179) notes that:

All the works [discussed by Blackburn] have some 'acousmatic' ... quality to their timbre, although the only work in this selection which has an overt acousmatic intent is Vanitas [by Steve Everett]. Everett, in the performance notes to the score, requests that speakers are concealed around the organ case so that all sounds, acoustic and electronic, appear to emanate from a single physical location.

In his view, co-location reinforces acousmatic perception.

The second meaning of 'acousmatic' has been coined by Schaeffer (1966) and linked to a different philosophical tradition. In Schaefferian terminology, acousmatic listening is associated to écoute réduite (reduced listening), meaning (following Husserl's phenomenology concept of reduction or épochè) that the objet sonore is perceived for itself, for its sonic qualities and abstract from instrumental causality. This Schaefferian definition contradicts the Pythagorean definition, in which the cause is unseen but otherwise clearly identified and foreseeable. The Schaefferian definition also contradicts Husserlian phenomenological reduction. The épochè requires that the objet sonore is perceived for itself, for its sonic qualities, abstract from instrumental causality, and most importantly, abstract from intentionality. The second meaning of acousmatique is restricted to '[a] situation of pure listening, without the attention being able to derive of, or be reinforced by, a visible or foreseeable instrumental causality' (Bayle 1993:179). This definition is setting aside intentionality, which is essential to phenomenological reduction. Therefore, as Kane (2007: 22) pointed out, the common usage of the word acousmatique or objet sonore in music now may differ from the initial concept of reduced listening: 'the phenomenological aspects of Schaeffer's work transform this project [to create a 'hybrid discipline' capable of grounding both acoustics and musical practice] into a mythical thinking, where history is wholly absent'.

Then again, the opposition between reduced versus causal listening (Chion, 2015) in the acousmatic situation may have been overemphasised. According to Smalley (1997: 109):

However, what is and is not acousmatic is not clear-cut, since even music where live performers are involved can become acousmatic when the listener cannot connect the sounds heard with the observed physical activity which supposedly produces them. This can happen in live electronic music performance, and is a category of music I call live acousmatic music.

Perception of instrumental causality is clearly recognised and acknowledged in the case of the organ, even if sound sources remain hidden. In the ORA projects, it is reinforced because only sounds produced by the organ itself are amplified and used for live electronics, which is in accordance with the 'instrumentality' principle. However, the augmented organ may or may not be an acousmatic situation according to the second meaning (Bayle 1993: 179), because, depending on the music itself, a 'foreseeable instrumental causality' may or may not be perceived. It is possible to render the sounds less 'organ-like' or even to use the electroacoustic installation for diffusion of any music through the 'veil' of the organ façade. Smalley (1997: 112) observed:

Acousmatic music, therefore, can stay close to traditional, gestural cause-source relations, but at its most adventurous extends into third-order ambiguity and beyond to a music which, although remote from traditional sound making activity, can nevertheless maintain a humanity.

Finally, the acousmatic situation is often reported as visually unsatisfactory. However, it can be accompanied by visual effects and video art. Some of the ORA concerts were visually enriched with interactive video projections using dynamic projection mapping on the organ's façade (Jacquemin et al. 2010). Figure 1 shows the interactive video projection in Sainte Élisabeth. Video projection related to the sound tends to reinforce the perception of instrumentality and causality of the music and is probably detrimental to acousmatic listening per se.

\subsection{Performers' gestures and instrumental causality}

Playing the augmented organ is a somewhat unfamiliar experience for the organist. Remember the description of Merleau-Ponty (1958: 167-8) of an organist 'at home' with an unknown instrument':

an experienced organist is capable of playing an organ which he does not know ... He sits on the seat, works the pedals, pulls out the stops, gets the measure of the instrument with his body, incorporates within himself the relevant directions and dimensions, settles into the organ as one settles into a house ... Between the musical essence of the piece as it is shown in the score and the notes which actually sound round the organ, so direct a relation is established that the organist's body and

6 6This famous passage is quoted also in Blackburn $(2011,2017)$, although in a different direction. 
his instrument are merely the medium of this relationship.

This phenomenology of the instrument perception is no more valid in the case of the augmented organ because the sounds produced by the instrument can differ much from the ordinary organist's embodied experience. The pitch, timbre, timing, transients and all other qualities associated with a given key for a given registration can differ radically from an organist's expectations. This can be troubling, like a prepared piano. Contrary to the prepared piano situation, the preparation is not limited to a relatively small number of keys; it may change rapidly in time depending on the preset parameters or the computer musician's play.

Another type of creativity results from possibly no causal sound production in interactive instrumental music (Risset and Van Duyne 1996). Although the performer's gestures lose some causal agency, the instrumentality is preserved. It means that the organist's gestures are perceived even if they do not correspond to the organ's sound in the ordinary way. From the organist's side, this is demanding because the sound produced by the instrument is partly unpredictable: only the ear can help to adapt, memorise and finally master the situation, such as in improvisation générative (Savouret 2011). The organist must agree to be surprised and must be prepared to learn and change his or her habits. The sound spectromorphology (Smalley 1997), that is, motion, energy, direction, shaping and other attributes, are conveyed to the audience when the organist is able to get along to this new situation. If this is achieved, citing Merleau-Ponty (1958: 168), '[in] reality [the organ player's] movements during rehearsal are consecratory gestures: they draw affective vectors, discover emotional sources, and create a space of expressiveness as the movements of the augur delimit the templum'.

\section{CONCLUSION}

Augmented pipe organs offer a paradoxical listening experience of unity in the diversity: the music is at the same time 'electroacoustic' and 'instrumental'. Our work explores the aesthetics of 'fusion' between the acoustic and the electronic sources, that is, the acoustic sources sound electronic, and conversely, the electronic sources become indistinguishable from the acoustic sources. The augmentation allows for creating a wide variety of musical material, including micro-variations, dynamic nuances, overlaps, imitations, overlays, fluctuating intonations, mobile formants, spectral partials, echoes, and wind and breath noises. Extended playing techniques (such as wind effects from only partially pressed keys and drawn stops, manually controlled pumps, clusters, glides, attacks and anacrusis) create musical gestures that conjoin the heterogeneous sonic worlds of pipe organ and electronics. The first aesthetic principle, fusion, exploits the blending effect of the acoustic space surrounding the instrument; the room response transforms the sounds created by the many single sound sources into a consistent organ-typical soundscape at the listener's position. The second aesthetic principle, microphony, allows auditory intimacy: sounds are captured inside the organ case, close to the pipes or other types of instrumental noise. Subtle gestures of the performer are rendered audible. The third aesthetic principle, instrumentality, is to play organ generated sounds only. In this way, it has been possible to propose a taxonomy of new sounds and musical objects that others can reuse and that can form the beginning of an instrumentation and orchestration guide for this type of instrument/project.

The degree of fusion between the pipe organ and electronics differs from electric instruments ('electric sound') and mixed music ('acoustic instruments + live electronics'). In electric instruments (such as the electric guitar or keyboard synthesisers), the sound is coming clearly from loudspeakers, with no limitation in sound level and no reference to acoustic sound production. On the contrary, in the ORA project, the electronic sound is adjusted to the level of the acoustic sounds, achieving better fusion. In mixed music, the dialectic between acoustic and electronic sources is often emphasised at the expense of fusion. Think of works such as René Uijlenhoet's Dialogo Sopra I due Sistemi, or Boulez's dialogue de l'ombre double with its three dialectic words: 'dialogue', 'shadow' and 'double'.

Of course, other musical choices are possible using the same type of technical installation, but following different principles. Future work will develop in several, somewhat opposite, directions. One avenue is to continue exploration of digital audio effects applied to the pipe organ to complete the taxonomy. Acoustics and signal processing investigations are needed to better understand and control the interaction and feedback process. Another avenue is to reconsider and relax one or more of our principles: capture other sources of sound (i.e., relax the microphony principle), distribute loudspeakers in the surrounding space far from the organ case (i.e., relax the acoustic fusion principle) or to play back other sources of sound (i.e., relax the instrumentality principle) such as fixed sounds, synthesisers and other electronic or instrumental sources.

\section{REFERENCES}

1. Angster, J. Rucz, P. and Miklós, A. 2017. Acoustics of organ pipes and future trends in the research. Acoustics Today 13(1): 10-18.

2. Bayle, F. 1993. Musique acousmatique: propositions ... positions (Acousmatic Music: Propositions... Positions). Paris: Buchet/Chastel.

3. Blackburn, A. 2011. The Pipe Organ and Real-time Digital Signal Processing (DSP): An Organist's Perspective. Unpublished doctoral thesis, Griffith University, Australia.

4. Blackburn, A. 2017. The Representation of the Electronics in a Musique-mixte Environment: Analysing Some Ontological and Semiotic Solutions for performance. Proceedings of the Electroacoustic Music Studies Network Conference, Nagoya. www.ems-network.org (accessed 21 August 2018). 
5. Boulez, P. and Gerzso, A. 1988. Computers in Music. Scientific American 258(4): 44-51.

6. Bregman, A. S. 1990. Auditory Scene Analysis: The Perceptual Organization of Sound. Boston: MIT Press.

7. Chion, M. 2015. Sound: An Acoulogical Treatise. Durham, NC: Duke University Press.

8. d'Alessandro, C. 2011. Orgues, musiques et musiciens à Sainte Élisabeth, Paris: la Flûte Harmonique.

9. d'Alessandro, C. and Noisternig, M. 2012a. Orgue: intérieur/ extérieur. In S. Bianchini, N. Delprat and C. Jacquemin (eds.) Simulation technologique et matérialisation artistique, Une exploration transdisciplinaire arts/sciences. Paris: L'Harmattan.

10. d'Alessando, C., Noisternig, M., Le Beux, S., Picinali, L., Katz, B., Jacquemin, C., et al. 2009. The ORA Project: Audiovisual Live Electronics and the Pipe Organ. Proceedings of International Computer Music Conference, ICMC 2009. Montréal, Canada: ICMA.

11. Danksagmüller, F. 2018. www.danksagmueller.com/ (accessed 21 August 2018).

12. Fidom, H. 2017. The New Baroque Organ. Orgel Park Research Reports, Vol. 5 Part 1, 2nd edn. Amsterdam: VU University Press. www.orgelpark.nl/en/Wetenschap/ Research\%20Reports/The-New-Baroque-Organ (accessed 12 March 2019).

13. Jacquemin, C., Ajaj, R., Le Beux, S., d'Alessandro, C., Noisternig, B., Katz, B. and Planes, B. 2010. Organ Augmented Reality: Audio-Graphical Augmentation of a Classical Instrument. International Journal of Creative Interfaces and Computer Graphics (IJCICG) 1(2): 51-66.

14. Kane, B. 2007. L'Objet Sonore Maintenant: Pierre Schaeffer, sound objects and the phenomenological reduction Organised Sound 12(1): 15-24.

15. Kane, B. 2014. Sound Unseen. Acousmatic Sound in Theory and Practice. New York: Oxford University Press.

16. Karplus, K. and Strong, A. 1983. Digital Synthesis of Plucked String and Drum Timbres. Computer Music Journal 7(2): 43-55.

17. Katz, B. F. G. and d'Alessandro, C. 2004. Apparent Source Width and the Church Organ. Proceedings of the Joint Annual Conference of the French and German Acoustical Societies. Strasburg, France: CFA/DAGA.

18. Lippe, C. 1991. Real-time computer music at IRCAM. Contemporary Music Review 6(1): 219-4. McCabe, S. L. and Denham, M. J. 1997. A model of auditory streaming. The Journal of the Acoustical Society of America 101(3): 1611-21.

19. Merleau-Ponty, M. 1958. The Phenomenology of Perception, trans. Colin Smith. London: Routledge \& Kegan Paul. Orig. pub. in French, 1945.

20. Miranda, E. R. and Wanderley, M. 2006. New Digital Musical Instruments: Control and Interaction Beyond the Keyboard. Aspen: A-R Editions.

21. Pollard, H. F. 1999. Tonal Portrait of a Pipe Organ. The Journal of the Acoustical Society of America 106(1): 360-70.

22. Puckette, M. S. 1996. Pure Data: Another Integrated Computer Music Environment. Proceedings of the 1996 International Computer Music Conference. Hong Kong: ICMA.

23. Puckette, M. 2007. The Theory and Technique of Electronic Music. Singapore: World Scientific Publishing.

24. Risset, J.-C. 2002. Examples of the Musical Use of Digital Audio Effects. Journal of New Music Research 31(2): 93-7.

25. Risset, J.-C. and Van Duyne, S. 1996. Real-Time Performance Interaction with a Computer-Controlled Acoustic Piano. Computer Music Journal 20(1): 62-71.

26. Sanfilippo, D. and Valle, A. 2013. Feedback Systems: An Analytical Framework. Computer Music Journal 37(2): $12-27$.

27. Savouret, A. 2011. Introduction à un solfège de l'audible, l'improvisation libre comme outil pratique. Lyon: Symétrie.

28. Schaeffer, P. 1966 Traité des Objets Musicaux. Paris: Seuil.

29. Smalley, D. 1997. Spectromorphology: Explaining Soundshapes. Organised Sound 2(2): 107-26.

30. Stockhausen, K. 1971a. Mikrophonie I (1965), für Tamtam, 2 Mikrophone, 2 Filter und Regler. In Texte zur Musik 3. Cologne: Verlag M. DuMont Schauberg.

31. Stockhausen, K. 1971b. Mikrophonie II (1965), für Chor, Hammondorgel und 4 Ringmodulatoren. In Texte zur Musik 3. Cologne: Verlag M. DuMont Schauberg.

32. Symbolic Sound Corporation (2018) Kyma - a hardware and software environment for creative sound design, live performance, and scientific exploration. https://kyma.symbolicsound. com/ (accessed 21 August 2018).

33. Verfaille, V. Guastavino, C. and Traube, C. 2006. An Interdisciplinary Approach to Audio Effect Classification. Proceedings of the International Conference on Digital Audio Effects (DAFx-06). Montreal, Canada.

34. Walcker-Mayer, G. 2006. Ligeti und die Moderne Orgel. www.gewalcker.de/gewalcker.de/PDF_public/Ligeti- Orgel.pdf. (accessed 25 may 2018)

35. Walcker-Mayer, G. 2015. Kleine Geschichte der modernen deutschen Orgel. www.walcker.com/walckermagazin/ kleinegeschichte-der-modernen-orgel.html. (accessed 25 May 2018).

36. Zölzer, U. 2002 DAFx: Digital Audio Effects. West Sussex: John Wiley.

\section{DISCOGRAPHY}

37. d'Alessandro, C. and Noisternig, M. 2012b. Les douze degrés du silence. Audio CD. Paris: Hortus, Hortus96-CD. Of Pipes and Patches: Listening to augmented pipe organs 